\title{
Student's Conception about Friction Force Direction in Physics Education Sebelas Maret University
}

\author{
Puspita Septim Wulandari ${ }^{1}$, C Cari $^{2}$, Nonoh Siti Aminah ${ }^{3}$ \\ ${ }^{1,3}$ Physics Education Program, Postgraduate, Sebelas Maret University, \\ Jl. Ir. Sutami no 36 Kentingan Surakarta \\ ${ }^{2}$ Physics Program, Postgraduate, Sebelas Maret University, \\ Jl. Ir. Sutami no 36 Kentingan Surakarta \\ Email : septim.puspita@gmail.com
}

Received 25 August 2017, Revised 22 September 2017, Accepted 1 October 2017

\begin{abstract}
The student's conception of friction force direction on objects is different. Student's conceptions are important to improve the next learning process. The aim to the research was to know student's conception about friction force direction. This research was a qualitative descriptive. Samples consisted of 33 students from Physics Education UNS semester 1 who have not obtained the material friction in the lecture. Data collected through test and intervie. Data were analyzed by reduction, presentation, conclusion and verification. Based on the result of student conception showed the average of $82,82 \%$ student can describe the direction of friction force on objects with translational motion, $18,18 \%$ student can describe the direction of friction force on objects with translational and rotation motion inclane and all students can not describe the direction of friction force on bicycle wheels.
\end{abstract}

Keyword: Bicycle, conception, friction force, rotate motion, translation motion.

\section{Introduction}

Students have different conceptions of objects or phenomena. The student's conception was depend on the preconceptions or the initial concept. If students have correct preconception, so it can support learning. If preconceptions are incorrect, so it will make students difficult to understand new concepts. These difficulties are provided an opportunity for students to experience a sustainable misconception. Handhika J. et al, (2015) argue that student conception is information that must be known before learning, so that lecturers will be easier in learning process. Nik (2015) to identify student ideas in advance is very important to be able to teach physics effectively. Student conceptions is important to evaluate progress in learning (Tzung-Jin Lin, 2017). Learning on Physics education recommends using several respresentations to know the conception of students, for example is free diagram. Rosengrant (2009) said that the use free diagrams can help teachers to know the students conception and help students to answer the problem. 
Friction force is one of the fundamental matter in physics learning. Friction force is often applied in everyday, but students still show problems and misconceptions about frictional force (Salazar, 1990). In physics books is often explained that the direction of friction forces against the direction of motion. According to Paulo and Andriano (2005) students were understand that friction forces are generally opposed to the objects motion. Paulo and Andriano (2015) is explained student conceptions about the frictional force of rotating objects and provide learning strategies. According to Cross (2017) the origin concept of the friction force is unclear, so he was investigated about the origin of frictional forces. Ambrosis et al. (2015) and Prasitpong et al (2010) were explained a simple demonstration to visualize the direction of frictional force because students have not understand the frictional force concept. In this research aim is to know student conception about friction force direction through free body diagram.

\section{Research Method}

The descriptive qualitative method was employed in this study. Data were collected through test and interview. The test was given by students to describe thefrictional force direction through free-body diagrams. Interviews were conducted to clarify students' answers. Samples were used 33 students of Physics Education UNS semester 1 who have not obtained the friction concept in the lecture. Data were analyzed by data reduction, data presentation, conclusion and verification (Sugiyono, 2010).

\section{Result and Discussion}

The result was shown by Figure 1 .

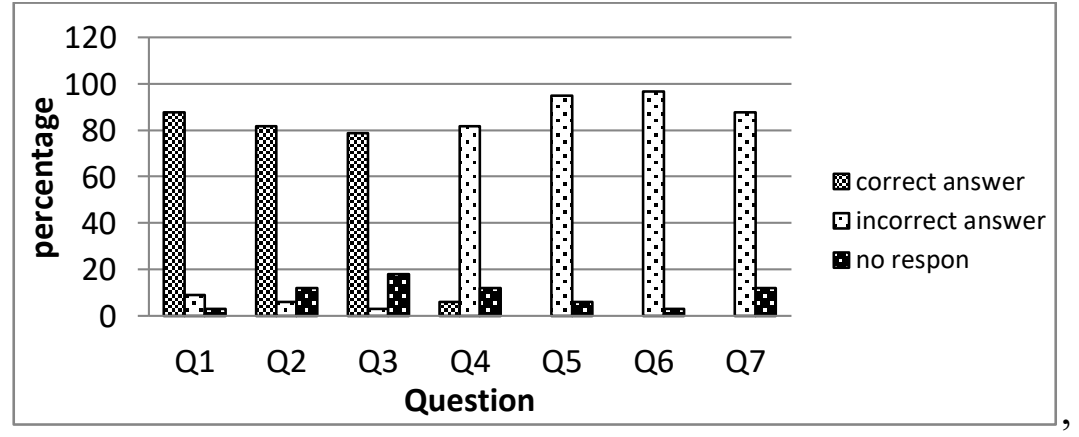

Figure 1. Analysis about student answers to each question

Figure 1 was shown that majority students can answer correctly Q1, Q2 and Q3 about the frictional force direction on translational motion. Students can not answer in Q4, Q5, Q6 and Q7 because the question involves on rotation motion. 


\section{1. frictional force direction on translation motion}

Table 1. The result of the frictional force concept on translation motion

\begin{tabular}{|c|c|}
\hline Test & Result \\
\hline $\begin{array}{l}\text { Q1. A block } \mathrm{m} \text { in the rough horizontal plane. Draw } \\
\text { the forces that act (including frictional force) on } \\
\text { the block in the horizontal plane, when: } \\
\text { a. the block was given force to the positive } \mathrm{x} \text { axis } \\
\text { b. the block is given force to the negative } \mathrm{x} \text { axis }\end{array}$ & $\begin{array}{l}87.88 \% \text { correct. } 9.09 \% \text { incorrect } \\
\text { and } 3.03 \% \text { did not give a clear } \\
\text { answer. }\end{array}$ \\
\hline $\begin{array}{l}\text { Q2. A block } m \text { is placed on a rough incline. Draw } \\
\text { the forces that act (including frictional forces) on } \\
\text { the block, when: a. down and b. up }\end{array}$ & $\begin{array}{l}81.81 \% \text { correct answer. } 6.06 \% \\
\text { incorrect and } 12.12 \% \text { no respon }\end{array}$ \\
\hline $\begin{array}{l}\text { Q3. Draw the forces that act (including frictional } \\
\text { forces) on a solid cylinder which translation motion } \\
\text { on the incline }\end{array}$ & $\begin{array}{l}78.78 \% \text { correct answer. } 3.03 \% \\
\text { incorrect and } 18.18 \% \text { no respon }\end{array}$ \\
\hline
\end{tabular}

The student showed the frictional force direction on translation motion (according to Q1, Q2 and Q3). The average student can draw the friction force direction correctly, although some students give the wrong answer. Students conception with correct answer was the friction force against the objects motion. If the object moved to the right, so the friction force to the left. If the object moved to the left, the friction force to the right. Base on interview result, the student answered incorrect because of the confused and forgot friction concept.

The correct concept, friction force direction is not against the direction of the object motion. The friction force direction is opposite to the force that causes the object to move. The cause of moving objects in Q1, Q2, and Q3 is the force applied to the object. The force is applied to the right, friction force to the left. If the force is to the left, the frictional force to the right. Student conception is different with the concept of frictional force direction. Q1, Q2 and Q3 indicated that the force is in the direction of the object motion, so that almost all students give the correct answer.

\subsection{Rotation and translation in the incline}

Table 2. Conception of frictional force direction in rotation and translation in the incline

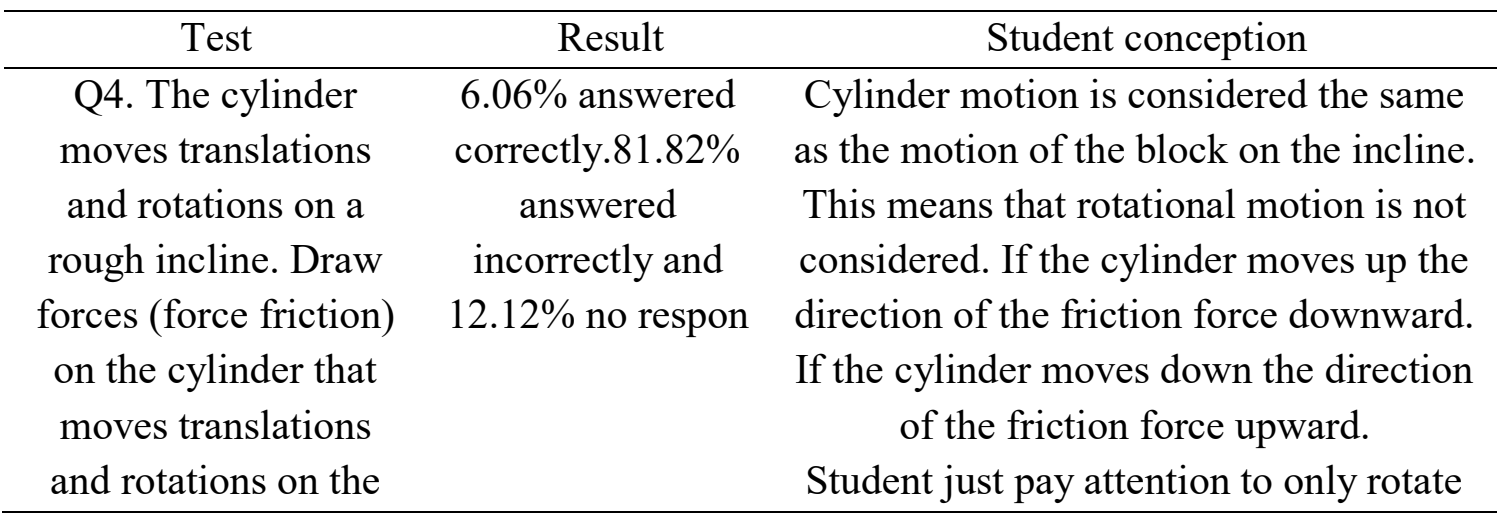




\begin{tabular}{|c|c|c|}
\hline Test & Result & Student conception \\
\hline $\begin{array}{c}\text { incline, if cylinder } \\
\text { down and cylinder up }\end{array}$ & & $\begin{array}{l}\text { motion. The cylinder moves down, the } \\
\text { direction of the frictional force } \\
\text { downward. Cylinders move upwards } \\
\text { direction of friction force upward. }\end{array}$ \\
\hline
\end{tabular}

The correct concept is the direction of friction force on different cylinders with block. The moving block down in the incline, the direction of the friction force is up. If the block moves up, then friction force downward. Cylinders moved up / down in the incline plane will experience rotate motion and translation. Cylinders have torque at the center of mass whose value is not equal to zero. Cylinder rotation motion because there is a force. The force is the frictional force. The cylinder that moves down on the inclined plane has a frictional upward force direction because the torque at the center of the mass accelerates the cylinder movement. Cylinders that move up, cylinder rotate motion will slow or decrease. The decreasing rotational motion indicates that the angular acceleration in the cylinder is negative. Negative angular acceleration can be achieved if the friction force points upward.

\subsection{Friction force on bicycle wheel}

Table 3. The result of the frictional force concept on the bicycle wheel

\begin{tabular}{cc}
\hline Test & Result \\
\hline $\begin{array}{l}\text { Q5. The bike moves to the left like Figure 2. Draw } \\
\text { the forces (frictional force) on both bicycle wheels. }\end{array}$ & $\begin{array}{c}93.94 \% \text { incorrect }(72.73 \% \\
\text { students answered the } \\
\text { frictional force direction to } \\
\text { the right/back and } 21.21 \% \\
\text { answered the frictional force } \\
\text { direction to the left/forward) } \\
\text { and } 6.06 \% \text { no respon }\end{array}$
\end{tabular}

Figure 2. Bicycle two wheels

(Source: www.google.com)

Q6. The bike will start moving toward the negative $\mathrm{x}$ axis as shown in Figure 6. The first wheel (front wheel) is not connected to the chain, while the second and third wheels are connected to the chain

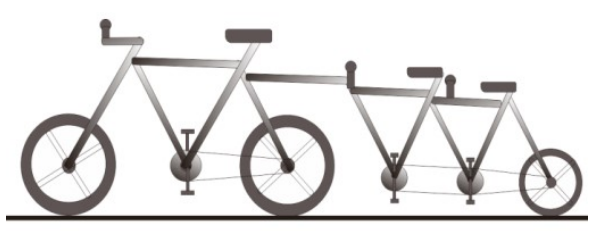

Figure 6. Bicycle three wheels each wheel on the bike.

\begin{abstract}
$96.97 \%$ incorrect $(72.73 \%$ students answered the frictional force direction to the right/back ans $24.24 \%$ answered the frictional force direction to the left/forward) and $3.03 \%$ no respon
\end{abstract}




\begin{tabular}{cc}
\hline Test & Result \\
\hline $\begin{array}{c}\text { Q7. Figure 7 is a picture of a two-wheeled bicycle } \\
\text { with a bicycle pedal on the front wheel }\end{array}$ & $\begin{array}{c}93.94 \% \text { incorrect }(72.73 \% \\
\text { answered the direction of the } \\
\text { frictional force on both rear } \\
\text { wheels and } 15.15 \% \text { answered } \\
\text { the direction of the frictional } \\
\text { force on both wheels } \\
\text { forward. }\end{array}$ \\
$\begin{array}{c}\text { Figure 7. two-wheeled bike with a front-wheel drive } \\
\text { (Source: www.google.com) }\end{array}$ & $\begin{array}{c}12.12 \% \text { did not give a clear } \\
\text { answer }\end{array}$ \\
Draw the forces (including the frictional force) on \\
each wheel on the bike.
\end{tabular}

Student conception in Q5, 93,94\% student have conception which less appropriate with concept of direction of friction force on bicycle wheel. Students draw the direction of the frictional force on the front wheel and the rear wheel toward the rear/right, as in Figure 3

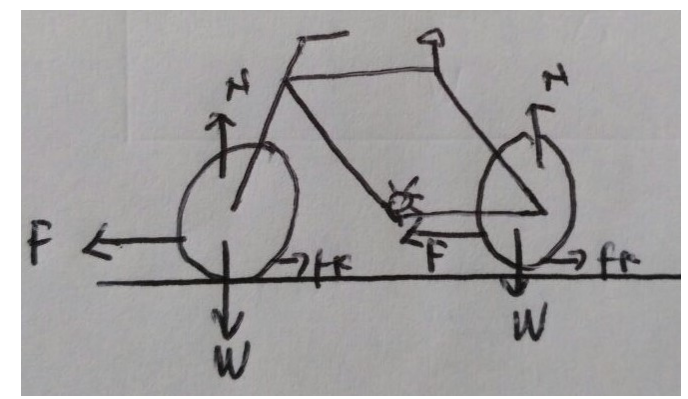

Figure 3. An example of a student's answer. the direction of the frictional force backward/right

The student replied as Figure 3 because the direction of the friction force is opposite to the direction of the motion of the bicycle. Questions Q5 bikes move to the front/left, so according to the students is friction direction towards the back/right. Students do not consider the motion of rotation on the rear wheels. Students only consider translational motion on the bike. Students assume bike motion such as block motion. The assumption makes students have a conception, the bike move to the left will have a friction force to the right. Students answer the direction of the frictional force on both bicycle wheels towards the front/left, as shown in Figure 4. 


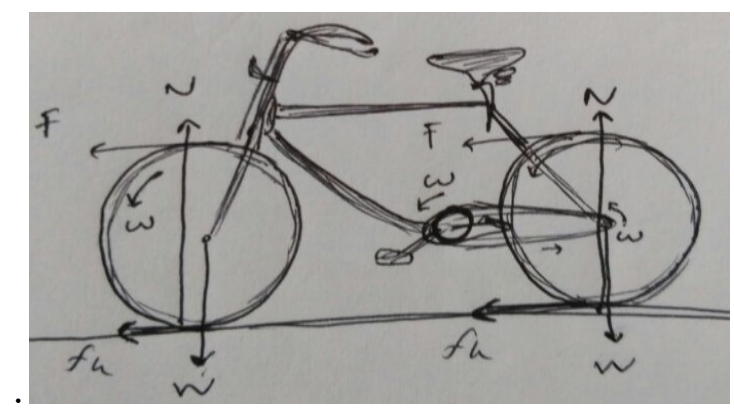

Figure 4. Examples of student answers, the frictional forces direction to forward / left

Students have opinion that the move wheel front/left has the acceleration to counterclockwise. As a result friction force towards the front/left (interview). 6.06\% of the students had unclear answers and did not describe the direction of frictional forces, such as Figure 5.

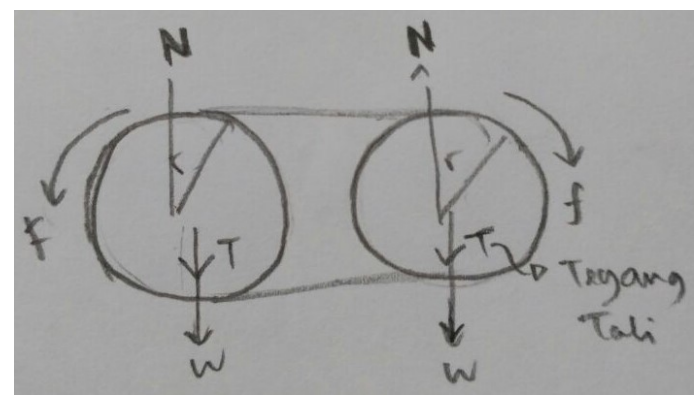

Figure 5. Did not give a clear answer about the direction of frictional force

The result of the interview is the student forgot with the concept of friction force, confused command problem and describe it.

Question Q6 illustrates the direction of the frictional force on a bycycle that runs toward the negative $\mathrm{x}$-axis as Fig. 6 . The result of the answer in Table 3 showed that no student can correctly explain the direction of the frictional force. $72.73 \%$ of students answer the direction of the friction force on the three wheels towards the back / right. The result of the interview is the concept of frictional force as opposed to the direction of motion. The bycycle moved towards the front/left, then the friction force on the wheel back/right. Students $21.21 \%$ answered the direction of the friction force on the three wheels to forward/left. Students opinion, if bicycle is moved to the front/left, the wheel will rotate counterclockwise. The direction of the rotation of the wheel causes the direction of the friction force towards the front/left. There are also $3.03 \%$ of students who do not clearly describe the direction of frictional forces. The student said he forgot about the concept of friction and confused.

Q7 illustrates the direction of the frictional force on a bicycle to the negative $\mathrm{x}$-axis. The bicycle pedal on the front wheel like Figure 7. Table 3 shows $93.94 \%$ of students describe the direction of friction on the wheel with incorrect answers. The student's answers are different. Students describe the direction of the frictional force on both bicycle wheels towards the back/right. According to students friction force is a forcethat inhibits the movement and its direction contrary to the direction of motion (interview). 
In addition, students describe the direction of the friction force on the two wheels front/left. The reason is that the wheel spins towards the front/left so that the direction of the friction force towards the front/left. $12.12 \%$ of students no response because confused with the picture of the bike.

Table 3, students mentioned that the frictional force is opposed to the motion, such as alternative concepts reported by other researchers (Cross, 2017). Almost all the students gave a less precise answer on Q4, Q5, Q6 and Q7, although there are students who can explain the process of the bike motion. There are two variations of incorrect answers. The first is that the students only pay attention to the translational motion so the frictional force is opposite to the motion direction. Second, the students only pay attention to the rotate motion on the wheels so that the direction of the friction force to the left. Students who do not describe the direction of friction because forgot the concept of friction force, did not understand the intent of the problem that has been given.

\subsection{The concept to solve the question about the frictional force direction on the bike}

Handhika (2017) explains that the bike events are moved, the frictional force on the front wheel is different from the back wheel. The direction of the frictional force backward for the front wheel and forwards for the rear wheels. Prasitpong (2010) visualizes the direction of the frictional force on the bicycle wheel, shown in Fig. 8 and Fig. 9.
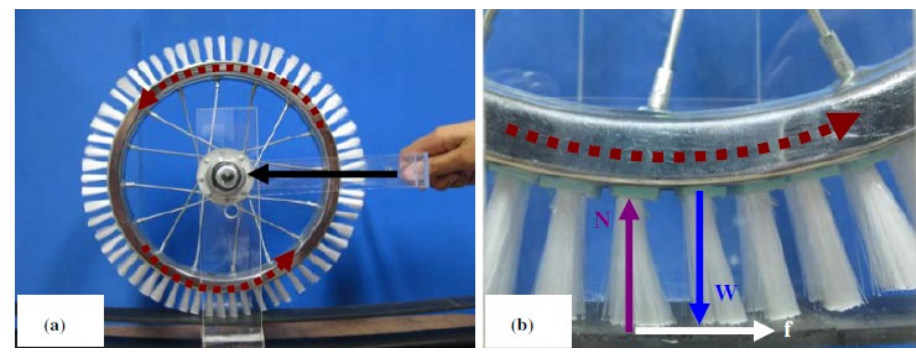

Figure 8. (a) front wheel circuit. (b) The direction of friction force. $W=$ weight, $N=$ normal force and force $\mathrm{f}=$ friction.

(Source: Prasitpong et al, 2010)

Figure 8 (a) shows the front wheel driven by the handle. The handle is connected to the wheel axle. When the grip is pushed to the left, the wheels move translations and rotations. The motion of the front wheel motion was caused by force act on the wheel axle. The rotate motion was caused by the friction force between the surface of the rubber plate and the tip of the bristles. Without friction, the wheel moves to the left but does not rotate. Figure 8 (b) showed the direction of the frictional force. The bristles tip leads to the right, so that the direction of the front wheel friction towards the right. 


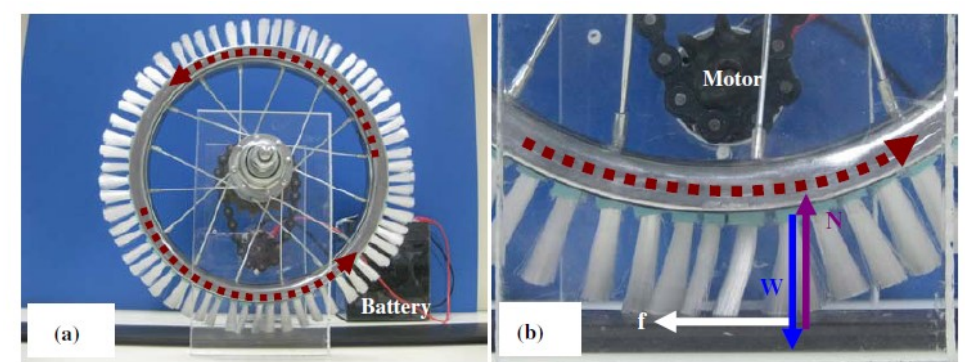

Figure 9 (a) Rear wheel . (b) rear wheel free body diagram. $\mathrm{W}=$ weight, $\mathrm{N}=$ normal force and force $\mathrm{f}=$ friction.

(Source: Prasitpong et al, 2010)

The direction of the frictional force on the rear wheel of the bike is shown in Fig. 9 (a). The bicycle pedal will move the chain, so the wheel rotated counterclockwise. The rubber surface gives the frictional force on the tip of the bristles, leading to the left side. If there is no friction force then the wheel will spin freely. Figure 9 (b) shows the tip of the bristles pointing to the left, so that the direction of the friction force to the left.Simple explanation by considering the two-wheeled bike with mass $\mathrm{m} 1$ and $\mathrm{m} 2$, connected by a body bike M. Figure 10 is a free body diagram on the bicycle wheel. The 2 wheels (rear) can move because of the torque acting on the wheels. The front wheel of the bike is not connected chain and free spinning. Then, both wheels exert a compressive force on a rigid body, so that the corresponding reaction force on the wheels is $\mathrm{T} 1$ and $\mathrm{T} 2$. If the bike goes to the left, the fundamental equation for translation, $\sum \bar{F}=m a$. There are force acting on the rear wheel. It is frictional force. If there is not frictional force on the rear wheel, the wheel can not be accelerated. The front wheels, none of the $\mathrm{W} 1, \mathrm{~N} 1$ or $\mathrm{T} 1$ styles contribute to the torque at the center of the wheel, but the frictional force exists. The use of the torque relation equation with moment of inertia $\tau=I \alpha$, where $a=\alpha R$. The cause of translation is the force of the bicycle frame acts on the axle wheel and a linear acceleration to the left. So it is showed that the frictional force on the front wheel $\mathrm{fl}$ must opposite direction with the force ie the direction to the right.

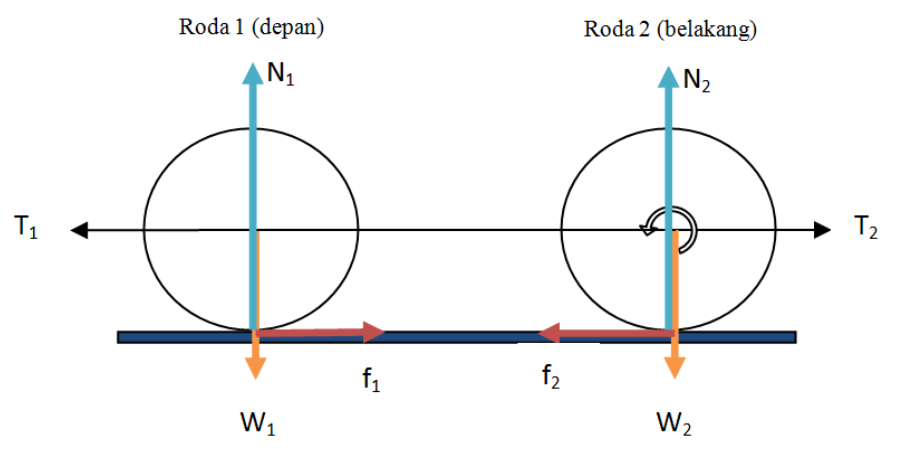

Figure 10. Free body diagram on a two-wheeled bicycle

The motion of the front wheel motion was caused by the skeletal force of the bicycle acting on the axle wheel. While the motion of the front wheel rotation was caused by 
the friction between the wheels and the ground. In other words, if the front wheel does not touch the ground, it will not be played at all. Finally, from both bicycle wheels indicates that they both rotate in the same direction but the direction of the frictional force on each wheel is opposite. Not all friction forces against motion. The direction of friction force was determined by the cause of the movement of the object, not the direction of the movement of the object.

Determined the value of frictional force, it can be observed that the moment of inertia on both wheels $I$ is equal. Total mass of bikes is $m=m_{1}+m_{2}+M$. Linear acceleration is

$a=\frac{\sum \bar{F}}{m}$

The friction force that occurs on the rear wheels is stronger than the front wheel. $\sum \bar{F}=f_{2}-f_{1}$, and $f_{2}-f_{1}>0$. Equation (1):

$a=\frac{f_{2}-f_{1}}{m_{1}+m_{2}+M}$

The wheels also move rotation. there is torque at the center of the wheel, using equations $\tau=F R$. Relationship between torque and inertia is $\tau=I \alpha$, and $\alpha=\frac{a}{R}$. Linear acceleration:

$\begin{aligned} \tau & =I \frac{a}{R} \\ a & =\frac{\tau R}{I}\end{aligned}$

Assumes the moment of inertia on both wheels through the center of mass is 2I. Then the moment of inertia is parallel with $\mathrm{R}$ is $I=2 I+m R^{2}$. Linear acceleration is

$a=\frac{\tau R}{\left(2 I+m R^{2}\right)}$

The relationship between torque and inertia is

$\tau=I \alpha$

If $\tau=R f_{1}$ and $\alpha=\frac{a}{R}$, so equation (6) can write:

$R f_{1}=I \frac{a}{R}$

Substitution of equation (5) to equation (7) to obtain frictional force values on the front wheel.

$R f_{1}=I \frac{\left(\frac{\tau R}{\left(2 I+m R^{2}\right)}\right)}{R}$

$R f_{1}=\frac{\tau I}{2 I+m R^{2}}$

$f_{1}=\frac{\tau I}{\left(2 I+m R^{2}\right) R}$

Substitution equation (5) and (8) to equation (2) to know friction force in rear wheel.

$\frac{\tau R}{\left(2 I+m R^{2}\right)}=\frac{f_{2}-\left(\frac{I \tau}{\left(2 I+m R^{2}\right) R}\right)}{m}$ 
$f_{2}=\left(\frac{\tau R}{\left(2 I+m R^{2}\right)}\right) m+\frac{I \tau}{\left(2 I+m R^{2}\right) R}$

$f_{2}=\frac{\tau}{\left(2 I+m R^{2}\right)}\left(m R+\frac{I}{R}\right)$

$f_{2} R=\frac{\tau}{\left(2 I+m R^{2}\right)}\left(m R^{2}+I\right)$

$f_{2}=\frac{\tau\left(m R^{2}+I\right)}{\left(2 I+m R^{2}\right) R}$

Equation (8) is the friction force in the front wheel. Equation (9) is the value of the friction force on the rear wheel.

\section{Conclusion}

Direction of frictional force on the rolling object was assumed to be equal to the direction of the frictional force on the translation object. The result is $82.82 \%$ students could describe the direction of friction force on moving objects translations, $18.18 \%$ students could describe the direction of friction force on moving objects rotational translations in the incline. all students could not describe the direction of friction on a bicycle wheel. Student conception is the direction of friction force opposite to the direction of motion. Students did not pay attention to the force direction that causes objects to move.

\section{Suggestion}

Suggestions for next research is to test the students conception using the frictional force equations on objects for translations and rotations.

\section{References}

Ambrosis, A. De, \& Malgieri, M. (2015). Investigating the role of sliding friction in rolling motion : a teaching sequence based on experiments and simulations. European Journal of Physics, 36(3), 35020. https://doi.org/10.1088/01430807/36/3/035020

Carvalho, P. S., \& Sampaio, A. (2005). Rotation in secondary school: teaching the effects of frictional force P S Carvalho and A S Sousa, 40(3), 257-265.

Cross, R. (2017). Origins of rolling friction. Phys. Educ. 52 (2017)055001 (4pp)

Handhika J. (2017). Modul Fisika dasar: pokok bahasan kinematika dan dinamika berbasis oasis. Yogyakarta: Azyan mitra media.

Handhika J, Purwandari, Cari, Suparmi \& Sunarno. (2015). Profil Konsepsi Mahasiswa Pada Materi Kinematika, hlm. 167-172. Prosiding Seminar Nasional Pendidikan Sains (SNPS). UNS

Lin, T., Tan, A., Lee, M., Tsai, C., Tan, A., Lee, M., \& Tsai, C. (2017). Evaluating and comparing Singaporean and Taiwanese eighth graders ' conceptions of science assessment. Research in Science \& Technological Education, 5143(May), 118. https://doi.org/10.1080/02635143.2017.1318363 
Prasitpong, S., Chitaree, R., \& Rakkapao, S. (2010). Studying the frictional force directions via bristles, 602 .

Rosengrant D. (2009). Do student use and understand free-body diagrams?. Physics Education Research 5, 010108.

Salazar, A. (1990). Is the frictional force always opposed to the motion ? P-, 82(1990), $1-5$.

Sugiyono.2010. Memahami Penelitian Kuliitatif. Bandung: Alfabeta 